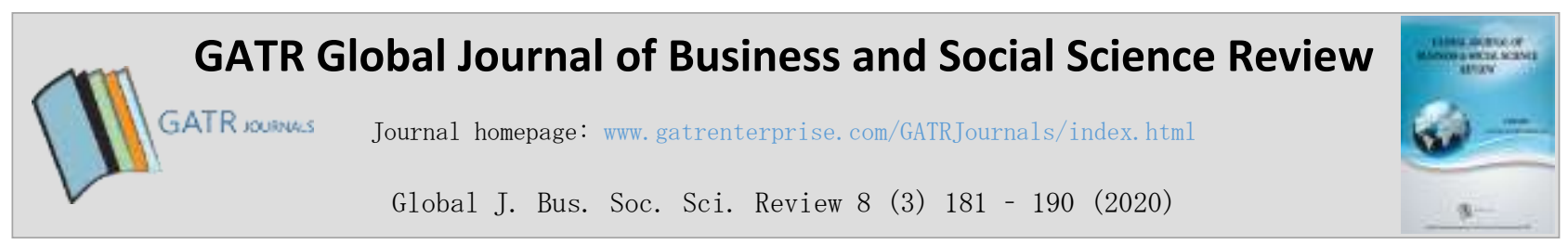

\title{
Research Synthesis on Educational Models
}

\author{
Chaiwichit Chianchana
}

Faculty of Technical Education, King Mongkut's University of Technology North Bangkok, 1518 Pracharat Sai 1 Road, Bangsue, Bangkok, 10800, Thailand

\begin{abstract}
Objective - The purpose of this research is to evaluate research on educational models, to study the effect of the research characteristics on educational models, and to synthesize the research methods and presentations about educational models through qualitative synthesis by content analysis.

Methodology/Technique - The sample was research on educational models on the type of thesis at the graduate level from 2013 to present. The research instruments took three forms. The data analysis method used was the ATLAS.ti program using content analysis, frequency, and percentage.

Finding - The results show that: 1) The research evaluation on educational models the most of the research used to synthesize research at a very good level, 2) The most research characteristics: research issue was personality traits, research problem presentation was the characteristic of the research problem presentation reflecting the importance of the study, setting research objectives was the study the composition/indicators, develop the model and study the use of the model, and research conceptual framework was the bringing each concept/component together, 3) The most common research methodology applied in the research was research and development (method), focus group discussion (technique), an expert (sample), purposive sampling (sampling), interviews (tool), mean and standard deviation (data analysis), one-group pre-test/post-test design (research design), and 4) there were 8 types of research result presentations on educational models which were descriptive characteristics, causal relationship, the proposed process steps as objective, design characteristics on standard/indicators/factors of model.
\end{abstract}

Novelty - The qualitative characteristics, system approach characteristics, experimental characteristics, and mixedmethod between quantitative and qualitative methods.

Type of Paper: Empirical.

JEL Classification: A20, A39.

Keywords: Research Synthesis; Educational Model; Evaluative Research; Research Characteristics; Research Methodology; Research Result Presentation.

Reference to this paper should be made as follows: Chianchana, C. (2020). Research Synthesis on Educational Model, Global J. Bus. Soc. Sci. Review, 8(3): 181 - 190. https://doi.org/10.35609/gjbssr.2020.8.3(5)

\section{Introduction}

The concept of study management according to the National Study Plan, based on the key principles of study management, consists of the Principles of Education Management for The Nation Principles of Education Management for Equality and General based on the philosophy of sufficiency economy and the principle of participation in all sectors of society.

\footnotetext{
* Paper Info: Revised: June 15, 2020

Accepted: September 30, 2020

* Corresponding author: Chaiwichit Chianchana

E-mail: chaiwichit.c@fte.kmutnb.ac.th

Affiliation: Faculty of Technical Education, King Mongkut's University of Technology North Bangkok, Thailand.
} 
It also adheres to the sustainable development goals including domestic issues such as the quality of people of all ages. The national strategy is a key framework for the creation of a national education plan from 2017 to 2036, and the findings in the study's quality plan have also found that the development results are not satisfactory, as the basic academic achievements are significantly lower than average and lower than many Asian countries (Office of the Education Council, 2017). From that plan, it can be seen that education is extremely important and must continue to develop across all dimensions.

The challenges of education conditions continue to be developed. It requires a description of the various phenomena that are related to the study, which is characterized by the structural relationship of the components/variables/principles/concepts/functions that can describe the phenomenon of a particular subject. The above characteristics are called "models." Education-related models have challenges that require answers to what phenomena have been in recent years. When it comes to educational models that cover national strategy, there will be a lot of research. Modelling and development are caused by phenomena, whether natural or social, where the phenomenon is caused by variability. Change with interest influences other things. As a result, humans want to seek out the truth in that phenomenon, such as what components/variable elements/principles/concepts/functions. Is it relevant to reality or how to use it to describe, predict, control the phenomenon the so-called "model" is the source of the quest for answers by the modelling and development process (Chianchana, 2017).

Research synthesis is a research technique based on a scientific methodology. The research, focusing on the same research issue, studies statistical methods or methods of analyzing qualitative data and systematic conclusions. As a result, the answers to the research problems are more extensive and profound (Wiratchai, 1999). The aim of research synthesis to obtain a summary of the findings of previous studies.

Research on past models cover a wide range of issues. Both lectures and statistics cannot be summarized in the overall picture because they are largely scattered. No research has been taken to show the overall picture from the past to the present, and there is no overall synthetic summary to achieve new research knowledge. As a result of the lack of research synthesis, it is necessary to perform research synthesis where content analysis techniques are a clear method and procedures can provide answers to total conclusions. As a result of the synthesis of research, the research will provide an overview of educational models that will benefit the creation or development of educational models, as well as obtain information on how to model future research or developing research models.

The purpose of this research is to evaluate research on educational models, to study the characteristics of the research on educational models, and to synthesize research methods and presentations regarding educational models through qualitative synthesis using content analysis.

\section{Literature Review}

Research synthesis or research integration is the study of many research reports on the same issues to summarize the findings and summarize the similarities and differences between each research, as well as to explain the reasons for those differences and to gain knowledge that can be used extensively (Hunter, Schmidt, \& Jackson, 1982).

\subsection{Qualitative Research Synthesis}

Qualitative research synthesis aims to differentiate among methodologies (e.g., grounded theory, phenomenology, ethnography, narrative/discourse), study ontological positions, epistemological positions, paradigms of inquiry, foundational theories and philosophies (Crotty; 1998; Guba \& Lincoln, 2005). Methods for qualitative synthesis vary across a range of dimensions. Commissioners of qualitative syntheses might wish to consider the kind of product they want when selecting their method (Barnett-Page \& Thomas, 2009). 
Britten et. al. (2002) and Campbell et. al. (2003) have both conducted evaluations of meta-ethnography and claim to have succeeded, in using this method, to produce theories with greater explanatory power than could be achieved in a narrative literature review. This method has assumptions of grounded theory, as originally formulated and subsequently refined by Glaser and Strauss (1967). In addition, Kearney (2001) and Eaves (2001) adapted grounded theory to formulate a method of synthesis. Thematic Synthesis was developed from both meta-ethnography and grounded theory out of a need to conduct reviews that addressed questions relating to intervention needs, appropriateness and acceptability (Thomas \& Harden, 2008). Metanarrative synthesis arose out of the need to synthesize evidence to inform complex policy-making questions and was assisted by the formation of a multi-disciplinary team (Greenhalgh et. al., 2006). There is also content analysis, which text was condensed into fewer content-related categories (Evans \& Fitzgerald, 2002; Suikkala \& Leino-Kilpi, 2000). In addition, there is also Textual Narrative Synthesis, Meta-study, Ecological Triangulation, Critical Interpretive Synthesis and Framework Synthesis (Paterson et. al., 2001; Lucas et. al., 2007; Dixon-Woods et. al., 2006; Brunton et. al., 2006; Oliver et. al., 2008).

\section{Research Conceptual Framework}

This research synthesis is the synthesis of graduate research, both at the master's degree and doctorate levels in educational models, in which the educational model is a structure of the relationship of the components/variables/principles/concepts/functions that can explain the phenomenon of a particular subject related to the field of education.

The research is synthesized through a good level of the research assessment. This process is used to determine the value of educational model research in terms of accuracy, appropriateness and reliability. Further, the study of the research features consists of research issues, the research statement, research objectives, research variables, and research conceptual frameworks, and led to qualitative synthesis using content analysis, which is synthesized. The research method consists of research methods, techniques used in the research, samples, sampling, research instrumentation, data analysis, experimental design, research and research results presentation based on the educational models shown in Figure 1.

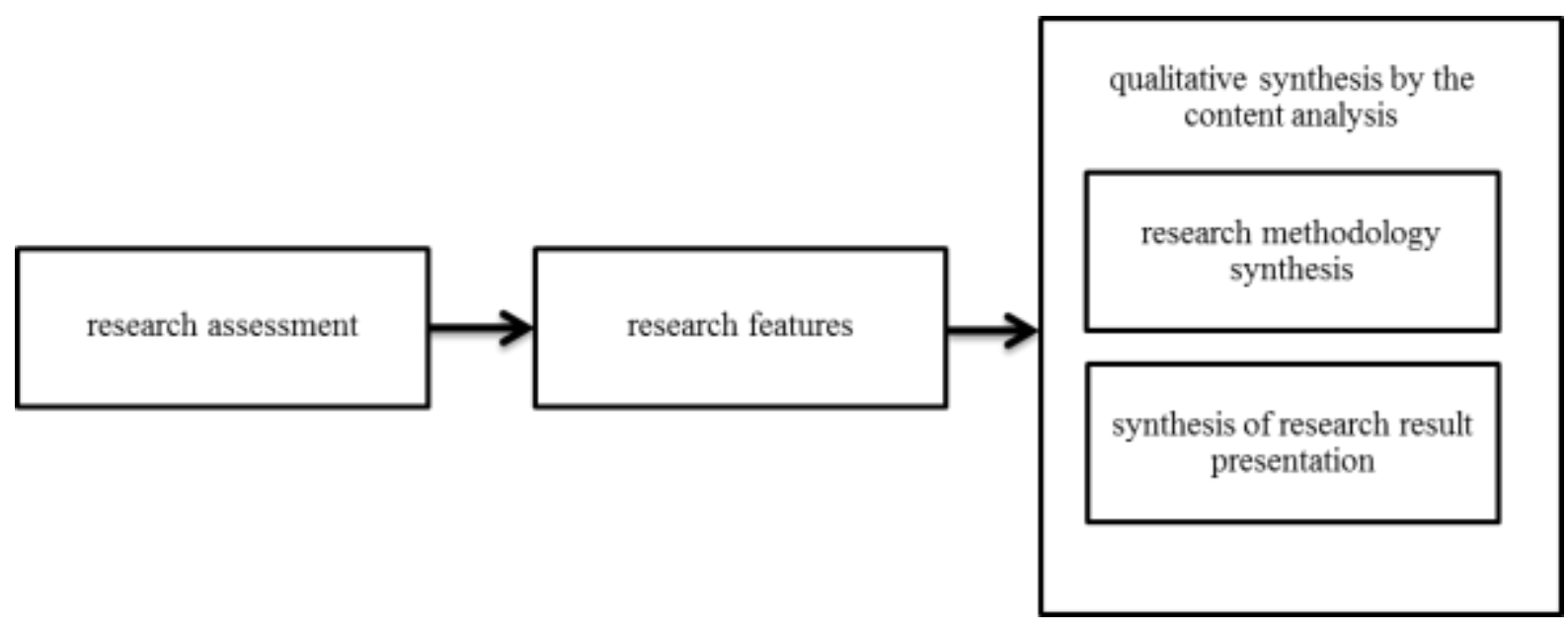

Figure 1. Research Conceptual Framework 


\section{Research Methodology}

\subsection{Sample}

The sample in the research was research on educational models on a certain type of thesis at the graduate level from 2013 to present, which can be searched from the Thai Library Network Website or ThaiLIS (www.thailis.or.th/tdc/).

\subsection{Instruments}

The research instruments took 3 forms: 1) the research quality evaluation form of the Office of the Education Council, developed by Wiratchai et. al. (2009) comprising of 30 items, which 5 levels and has been used to verify inter-rater reliability with 2 experts and 3 papers which found that the inter-rater reliability is $.89, .85$, and .90 respectively; 2 ) the research feature recording form has face validity equal to $.60-1.00$; and 3) the research methodology and the research result presentation synthesis form about educational models has a face validity equal to $.60-1.00$.

\subsection{Data Analysis}

The data analysis applied is the ATLAS.ti program using content analysis, frequency, and percentage.

\section{Results}

\subsection{Results of Research Assessment on Educational Models}

When evaluating the data, most of the research that synthesizes research was very good. The other two were not found in the research assumption of appropriate and rational research, and the writing of research limitations was accurate according to the research principles, as shown in Table 1.

Table 1. Research Assessment on Educational Models

\begin{tabular}{|c|c|c|c|c|}
\hline List & $\mathrm{n}$ & $\mathrm{Mean}$ & $\mathrm{S}$ & interpretation \\
\hline The title was clear and interest. & 53 & 4.00 & 0.00 & Very good \\
\hline $\begin{array}{c}\text { The background and importance of the problem are clear, in related } \\
\text { with the research. }\end{array}$ & 53 & 3.02 & 0.14 & Good \\
\hline $\begin{array}{c}\text { Research/objectives were consistent with the title, accurately based on } \\
\text { research. }\end{array}$ & 53 & 3.98 & 0.14 & Very good \\
\hline The reasons and necessity for doing research are reasonable. & 53 & 3.02 & 0.14 & Good \\
\hline The hypothesis was accurate, clear, according to research. & 8 & 4.00 & 0.00 & Very good \\
\hline Determine the scope of research appropriately and reasonably support & 53 & 3.34 & 0.48 & Good \\
\hline Terminology definitions were clear. & 53 & 4.00 & 0.00 & Very good \\
\hline $\begin{array}{c}\text { The framework of research concepts was accurate, clearly accurate } \\
\text { according to research principles. }\end{array}$ & 53 & 4.00 & 0.00 & Very good \\
\hline The relevant documents and research were sufficiently available. & 53 & 4.00 & 0.00 & Very good \\
\hline $\begin{array}{c}\text { Relevant documents and research were consistent with the problems or } \\
\text { objectives of the research. }\end{array}$ & 53 & 4.00 & 0.00 & Very good \\
\hline $\begin{array}{r}\text { Related documents and research were modern and linked to past } \\
\text { research. }\end{array}$ & 53 & 4.00 & 0.00 & Very good \\
\hline $\begin{array}{r}\text { Relevant documents and research in both Thai and international } \\
\text { countries had an appropriate proportion. }\end{array}$ & 53 & 4.00 & 0.00 & Very good \\
\hline Research design was consistent with research problems. & 53 & 4.00 & 0.00 & Very good \\
\hline The research process was clear. & 53 & 3.96 & 0.19 & Very good \\
\hline
\end{tabular}




\begin{tabular}{|c|c|c|c|c|}
\hline List & $\mathrm{n}$ & Mean & $\mathrm{S}$ & interpretation \\
\hline Define the population and sample groups appropriately for research & 53 & 3.91 & 0.30 & Very good \\
\hline Sampling samples and selection criteria were accurate. & 53 & 3.87 & 0.34 & Very good \\
\hline The tools used in the research were appropriate and quality. & 53 & 3.94 & 0.23 & Very good \\
\hline The process of collecting information was clear and appropriate. & 53 & 3.15 & 0.36 & Good \\
\hline $\begin{array}{c}\text { Statistics used to analyze data were accurate and appropriate for the } \\
\text { nature of the data. }\end{array}$ & 53 & 3.94 & 0.23 & Very good \\
\hline How to present the analysis translation & 53 & 3.92 & 0.27 & Very good \\
\hline The interpretation, meaning and summary of data analysis are clear. & 53 & 3.96 & 0.19 & Very good \\
\hline $\begin{array}{c}\text { The result was comprehensive in line with objectives and research } \\
\text { issues. }\end{array}$ & 53 & 4.00 & 0.00 & Very good \\
\hline $\begin{array}{c}\text { The discussion results were consistent with the research results and } \\
\text { cover research issues. }\end{array}$ & 53 & 3.94 & 0.23 & Very good \\
\hline The feedback was clear and helpful. & 53 & 3.96 & 0.19 & Very good \\
\hline It was practically useful research. & 53 & 4.00 & 0.00 & Very good \\
\hline It was academically beneficial research. & 53 & 3.96 & 0.19 & Very good \\
\hline The reporting pattern was academically correct. & 53 & 3.94 & 0.23 & Very good \\
\hline
\end{tabular}

\subsection{Result of Research Features on Educational Models}

Most of the research comprised of Ph.D. theses (83.20\%), Master's theses (16.98\%), and copyright between B.E.2556 - B.E.2561.

\subsubsection{Research Characteristics}

The most important research issue was characteristics. The remaining issues in order of importance were: Management, Quality Assessment and Assurance, Courses and Learning Management, Training, Health, Art, Culture and Community, Technology, Support, Education and Rights and Benefits, respectively.

\subsubsection{Research Problems}

According to the research synthesis, there were 4 characteristics: the nature of the presentation of the research problems reflecting the importance of the study, the nature of the presentation of the research problems reflecting the level of the problems (appear or no appear), the nature of the presentation of the problem-pointing research, and the characteristics of the presentation of problem-based research problems what were the specifics of the models/models, respectively.

\subsubsection{Research Objectives}

Based on the research synthesis, the most common characteristic was composition/indicators, develop patterns, and study the use of the model. This was followed by: the model development and testing, study problems/conditions/guidelines to develop models and study the results of the model, and characteristics of the problems/conditions/guidelines and development of patterns and evaluation, respectively.

\subsubsection{Research Conceptual Framework Characteristics}

According to the research synthesis, the most common of the concepts was the characteristics of each concept/composition, followed by characteristics of the relationship between the variables, characteristics based on the purpose of links to stages, and the characteristics of the system concept, respectively. 


\subsection{Results of Research Methodology Synthesis of Educational Models}

\subsubsection{Research Methodology Oriented on the Research}

According to the research synthesis, the focus of research that researchers applied in the research were as follows: $60.38 \%$ to research and development, $11.32 \%$ to descriptive research, $7.54 \%$ to mixed-method research, equally each $3.77 \%$ to casual research, development research and action research, and equally each $1.89 \%$ to qualitative research, and research and development, participatory action research, quantitative research, experimental research, evaluative research, and future research, as shown in Figure 2.

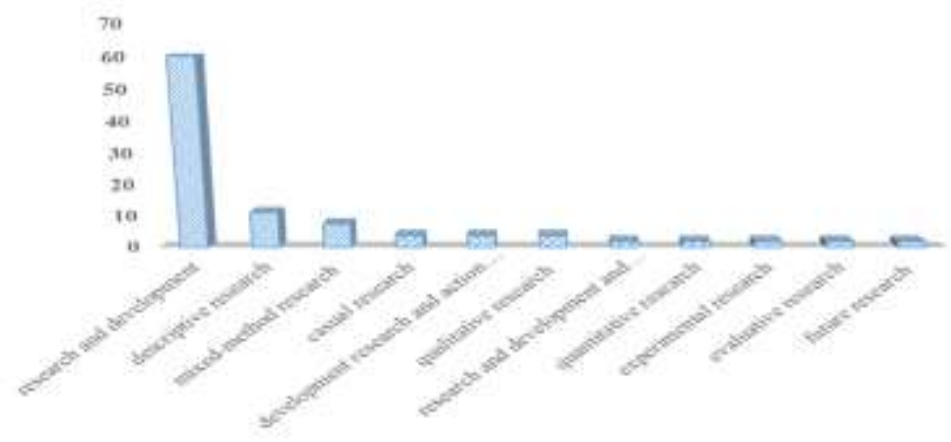

Figure 2. Percentage of research methodology applied on educational model research

\subsubsection{Techniques Used in the Research}

According to the research synthesis, the most commonly applied techniques in the research were as follow: $20.17 \%$ to focus-group discussion, $8.76 \%$ to interviews, $7.01 \%$ to Connoisseurship, $7.01 \%$ to best practices, $6.14 \%$ to structural equation model, $4.39 \%$ to data synthesis, $4.39 \%$ to exploratory factor analysis respectively, and other research techniques were available, as shown in Figure3.

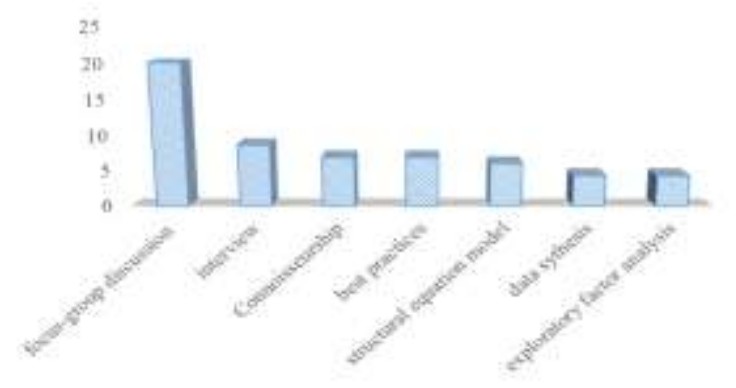

Figure 3. Percentage of techniques used on the research applied on educational model research

\subsubsection{Samples Used in the Research}

According to the research synthesis, the most common sample/target the researchers applied were as follows: $29.37 \%$ to experts (median $=9$ ), $13.99 \%$ to teachers (median $=88$ ), $11.19 \%$ to directors (median $=74$ ), and $7.69 \%$ to students (median=30), as shown in Table 2 .

Table 2. Sample characteristics used in research.

\begin{tabular}{|c|c|c|c|c|c|}
\hline sample & Frequency & Percentage & Max-Min & Mdn & Mo \\
\hline experts & 42 & 29.37 & $5-21$ & 9 & 9 \\
\hline teachers & 20 & 13.99 & $8-1300$ & 88 & - \\
\hline directors & 16 & 11.19 & $11-286$ & 74 & - \\
\hline
\end{tabular}




\begin{tabular}{|c|c|c|c|c|c|}
\hline sample & Frequency & Percentage & Max-Min & Mdn & Mo \\
\hline students & 11 & 7.69 & $5-917$ & 30 & 30 \\
\hline
\end{tabular}

\subsubsection{Sampling Used in the Research}

According to the research synthesis, the most common method of sampling was as follows: $60.82 \%$ to purposive sampling, $13.41 \%$ to multi-stage random sampling, $9.28 \%$ to stratified random sampling, $7.22 \%$ to cluster random sampling, $4.12 \%$ to simple random sampling, $3.09 \%$ to quota sampling, and $2.06 \%$ to volunteer sampling, as shown in Figure 4.

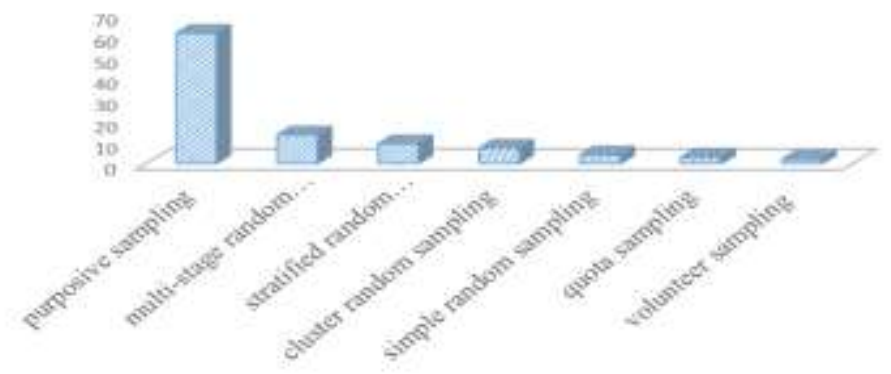

Figure 4. Percentage of sampling used on the research applied on educational model research

\subsubsection{Instrumentations Used in the Research}

According to the research synthesis, the most common instrumentations were as follows: $19.76 \%$ to structured interviews, $17.37 \%$ to questionnaires, $14.37 \%$ to evaluation forma, $10.18 \%$ to a rating scale, $9.58 \%$ to record forms, $6.59 \%$ to scales, and others, as shown in Figure 5.

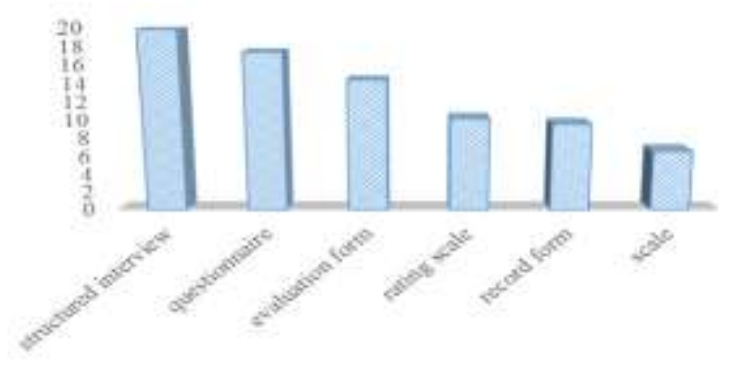

Figure 5. Percentage of instrumentation used on the research applied on educational model research

\subsubsection{Data Analysis Used in the Research}

According to the research synthesis, the most common methods of data analysis were as follows: $22.12 \%$ to mean, $22.12 \%$ to standard deviation, $21.15 \%$ to content analysis, $5.29 \%$ to percentage, $4.81 \%$ to t-test for dependent samples, $3.85 \%$ to structural equation model, $2.88 \%$ to confirmatory factor analysis, and others, as shown in Figure 6. 


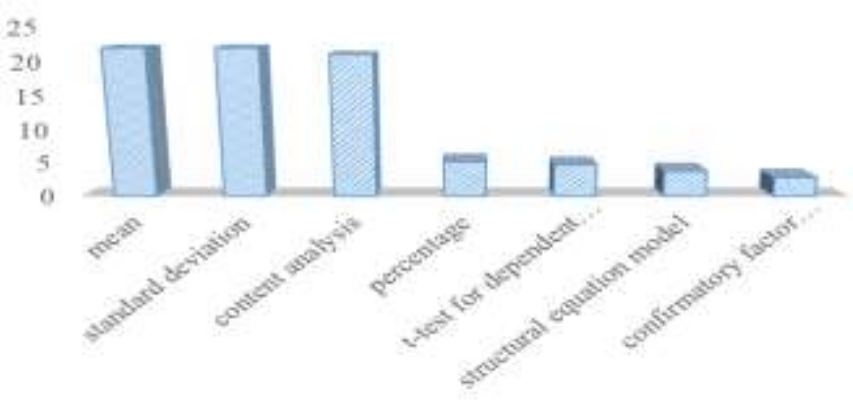

Figure 6. Percentage of data analysis used on the research applied on educational model research

\subsubsection{Experimental Design}

According to the research synthesis, the most commonly applied design is one group pre-test/post-test design $(39.97 \%)$ This was used $6.67 \%$ of the time.

\subsection{Synthesis Results of Research Result Presentation of Educational Model Research}

According to the research synthesis, the result presentations on the educational model were 8 characteristics as follows: description, casual connection of relationships, focus on processes or objectives, focus on standards/indicators/factors, quality, systematic approach, experiment, and mixed-methods.

\section{Discussion}

According to the findings, most of the research was taken at a very good level ( 23 items were good). This may be due to the fact that most of the research examined in this study was comprised of $\mathrm{PhD}$ theses. There is only a minority of the Master's thesis, which research thesis has a process of systematically conducting procedures through consultants and experts quite thoroughly through counselling. Therefore, the results of the research assessment are mostly at a very good level. Charoenphandhu (2005) has commented that 'Mentoring researchers was a "soft skill", a form of life skills, and more than just academic skills, which provide effective and productive forms of counselling that lead to the creation of people of the quality of society'.

According to the findings of this study, the research objective was to identify the most common characteristics of the study factors/indicators, development models, and to study the use of those models. This provides a step-by-step model for future research to obtain optimal results.

According to the research findings, the most common research method used by researchers is research and development $(60.38 \%)$. This may be because research and development methods is effective at achieving research objectives and producing educational research models. Pengsawat (2009) states that research and development is a process to develop and monitor product quality by conducting tests in real terms and improving several cycles of product improvement. Research and development is a systematic and ongoing study with 3 main processes: research, development and dissemination. Studying for new knowledge or understanding new aspects for product development and widespread transmission to users must be systematically and continuously done.

According to the findings of this study, the most commonly applied research technique is focus group discussions (20.17\%). This may be because group discussions provide the opportunity to gather specific information and correct any mistakes in real time. Urwongse (2019) states that focus-group discussions are a popular quality data collection method that focuses on discussions, debates, discussions of knowledgeable or experienced individuals on any point. Focus group discussions are commonly used in research that often has a gap of opinions and is used to study complex phenomena or behaviours or meaningful or diverse subjects. 
This is because it is a low cost method of study. Massey (2010) also states that the commentary of each level of data gives researchers an opportunity to clarify more things like finding out research on how group conversations make readers.

\section{Conclusion}

The results of the research show that: Most of the research used to synthesize research was of a very good level, consisting of 23 items, at a good level of 4 items. The most common research issue was personality traits. The most common research problem presentation was the characteristics of the research problem presentation reflecting the importance of the study. The most common research objective was to study the composition/indicators, develop a model and to study the use of the model. The most common research conceptual framework was the bringing of each concept/component together. The most common research method was research and development. The most common research technique was focus group discussions. The most common sample/informant design was experts. The most common sampling method was purposive sampling. The most common research tool was interviews (structured). The most common data analysis tools were mean and standard deviation and the most common research design was the one-group pre-test/post-test design. There were 8 types of research result presentations on educational models which were descriptive characteristics, causal relationship, the proposed process steps as objective, design characteristics on standard/indicators/factors of model, qualitative characteristics, system approach characteristics, experimental characteristics, and mixed-method between quantitative and qualitative methods.

This study makes the a few recommendations. As research essays are based on educational model research, this research has a variety of research practices. To write for research purposes on educational models, written guidelines should be developed in accordance with research issues, and applied appropriately in the context of the particular research. The research concept should be included in the written research model, to ensure clarity on the research objectives and methodology. Although the most commonly used research technique is focus group discussions, there are many other useful research tools and methods. Therefore, each research project should consider the appropriate research methodology on a case by case basis. The recommendations for future research are made. According to the findings of this study, the most commonly used research method is research and development. Future research should be synthesized in research issues that apply research and development methods. This research studies the nature and methods of conducting independent research, so to achieve a coherent dimension; it will be important to study the pattern of the relationship between research methods and research objectives to obtain a more consistent research design.

\section{Acknowledgement}

I would like to thank faculty of technical education for supporting the finance of this research.

\section{References}

Barnett-Page, E., \& Thomas, J. (2009). Methods for the synthesis of qualitative research: a critical review. BMC medical research methodology, 9(1), 1-11. https://doi.org/10.1186/1471-2288-9-59

Britten, N., Campbell, R., Pope, C., Donovan, J., Morgan, M., \& Pill, R. (2002). Using Meta ethnography to synthesise qualitative research: a worked example. Journal of health services research \& policy, 7(4), 209-215. https://doi.org/10.1258/135581902320432732

Brunton, G., Oliver, S., Oliver, K., \& Lorenc, T. (2006). A synthesis of research addressing children's, young people's and parents views of walking and cycling for transport.

Campbell, R., Pound, P., Pope, C., Britten, N., Pill, R., Morgan, M., \& Donovan, J. (2003). Evaluating metaethnography: a synthesis of qualitative research on lay experiences of diabetes and diabetes care. Social science \& medicine, 56(4), 671-684. https://doi.org/10.1016/S0277-9536(02)00064-3 
Chianchana, C. (2017). Creating and developing model. Silpakorn Educational Research Journal, 9(1), 1-11. https://so05.tcithaijo.org/index.php/suedureasearchjournal/article/ view/89954/70691.

Charoenphandhu, N. (2005). Mentor and coaches with a new generation of researchers.

Research Community, 134, 26.

Crotty, M. (1998). The foundations of social research: Meaning and perspective in the research process. Sage. https://seminariodemetodologiadelainvestigacion.files.wordpress.com/2012/03/the-foundations-of-social-research-

meaning-and-perspective-in-the-research-process-michael-crotty.pdf

Dixon-Woods, M., Cavers, D., Agarwal, S., Annandale, E., Arthur, A., Harvey, J., \& Riley, R. (2006). Conducting a critical interpretive synthesis of the literature on access to healthcare by vulnerable groups. BMC medical research methodology, 6(1), 1-13. https://doi.org/10.1186/1471-2288-6-35

J., Hsu, R., Katbamna, S., Olsen, R., Smith, L., Riley, R., \& Sutton, A.J. (2006). Conducting a critical interpretive synthesis of the literature on access to healthcare by vulnerable groups. BMC Medical Research Methodology. 6(35). 113. DOI: $10.1186 / 1471-2288-6-35$.

Eaves, Y. D. (2001). A synthesis technique for grounded theory data analysis. Journal of advanced nursing, 35(5), 654663. https://doi.org/10.1046/j.1365-2648.2001.01897.x

Evans, D., \& FitzGerald, M. (2002). Reasons for physically restraining patients and residents: a systematic review and content analysis. International journal of nursing studies, 39(7), 735-743. https://doi.org/10.1016/S00207489(02)00015-9

Glaser, B.G., \& Strauss, A.L. (1967). The Discovery of Grounded Theory: Strategies for Qualitative Research. New York: Aldine De Gruyter.

Greenhalgh, T., Robert, G., Macfarlane, F., Bate, P., Kyriakidou, O., \& Peacock, R. (2005). Storylines of research in diffusion of innovation: a meta-narrative approach to systematic review. Social science \& medicine, 61(2), 417-430. https://doi.org/10.1016/j.socscimed.2004.12.001

Guba, E.G. \& Lincoln, Y.S. (2005). Paradigmatic controversies, contradictions, and emerging confluences. In: Denzin, NK.; Lincoln, YS., editors. The Sage handbook of qualitative research. 3. Thousand Oaks, CA: Sage. 191-215.

Kaemkate, W. (2012). Research methodology in behavioural sciences. Bangkok: Faculty of education Chulalongkorn University.

Kearney, M. H. (2001). Enduring love: A grounded formal theory of women's experience of domestic violence. Research in nursing \& health, 24(4), 270-282. https://doi.org/10.1002/nur.1029

Hunter, J. E., Schmidt, F. L., \& Jackson, G. B. (1982). Meta-analysis: Cumulating research findings across studies (Vol. 4). Sage Publications, Inc. https://doi.org/10.3102/0013189X015008020

Lucas, P. J., Baird, J., Arai, L., Law, C., \& Roberts, H. M. (2007). Worked examples of alternative methods for the synthesis of qualitative and quantitative research in systematic reviews. BMC medical research methodology, 7(1), 4. https://doi.org/10.1186/1471-2288-7-4

Massey, O. T. (2011). A proposed model for the analysis and interpretation of focus groups in evaluation research. Evaluation and program planning, 34(1), 21-28. https://doi.org/10.1016/j.evalprogplan.2010.06.003

Oliver, S. R., Rees, R. W., Clarke-Jones, L., Milne, R., Oakley, A. R., Gabbay, J., ... \& Gyte, G. (2008). A multidimensional conceptual framework for analysing public involvement in health services research. Health Expectations, 11(1), 72-84. https://doi.org/10.1111/j.1369-7625.2007.00476.x

Office of the Education Council. (2017). National Education Plan B.E.2560-2579. Bangkok: Prigvan graphic.

Paterson, B. L., Thorne, S. E., Canam, C., \& Jillings, C. (2001). Meta-study of qualitative health research: A practical guide to meta-analysis and meta-synthesis (Vol. 3). Sage.

Pengsawat, W. (2009). Research and Development. SakonNakhon Rajabhat University Journal, 1(2), 1-12. https://ph01.tci-thaijo.org/index.php/snru_journal/article/view/10186.

Suikkala, A., \& Leino-Kilpi, H. (2001). Nursing student-patient relationship: a review of the literature from 1984 to 1998. Journal of Advanced Nursing, 33(1), 42-50. https://doi.org/10.1046/j.1365-2648.2001.01636.x

Thomas, J., \& Harden, A. (2008). Methods for the thematic synthesis of qualitative research in systematic reviews. BMC medical research methodology, 8(1), 45. https://doi.org/10.1186/1471-2288-8-45

Ketkanok Euawong. (2019). Group Discussion: Effective Qualitative Data Collection Techniques. STOU Education Journal, 12 (1), 17-30.https://so05.tci-thaijo.org/index.php/edjour_stou/article/view/182081.

Wiratchai, N. (1999). Meta-Analysis. Bangkok: Nichin Advance Tidal Group.

Wiratchai, N. \& others. (2009). Thai Education Quality Synthesis Report: Meta-Analysis. Bangkok: Office of the Education Council. 